\title{
SOCIETY AS AN ESSENTIAL ENVIRONMENTAL FACTOR (REVIEW)
}

\author{
Litovchenko O., Zub K., Zavgorodnii I., Myasoedov V.
}

\section{Kharkiv National Medical University, Kharkiv, Ukraine}

\begin{abstract}
The impact of environmental factors on humanity is considered as a world-wide challenge which requires to be addressed. The population that has greatly expanded its influence over the last century forms social component of environment. It includes such aspects as economic status of a region and of a particular person, education, level of stress, early life, living conditions, social support, nutrition, transport as well as health care system. All the concerns mentioned above and their effects on human health are actively being studied by various national and international organizations. It has been established that the categories of population of low socio-economic status and low level of social integration are affected much greater than those who are socially adapted. It is worth noting that social adaptation varies in countries with different level of economic development. Consequently, the state of health depends on social and economic situation of people. Perspective directions of social environment study are dedicated to identify the level of susceptibility of an individual to social influences. Worldwide entities aim to monitor the impact of social and psychological environment of different age categories, determine the long-term effect of such an impact. Thus, the forces of health protection organizations direct their forces towards improving health equally for all categories of population. Lack of awareness of all social influences on human health promotes further investigation in this field dedicated to elimination of inequalities of health maintenance.
\end{abstract}

Keywords: society, social environment, socio-economic status, social influence, human health, social diseases, environment.

Introduction. Nowadays the term "environment" is widely used within most of branches of human activity. The environment as well as its impact on people is largely discussed throughout the world on television and on the Internet. Global negotiations dedicated to environmental problems and their resolution are carried out by worldwide organizations [3, 9, 11]. The environmental issues in countries with poor economic development deserve special attention and often remain significant. Over the last century, the relationship between the environment, social organization and culture has been discussed in such areas as sociology, anthropology, geography and economics [3]. Thus the importance of the environment as a fundamental factor affecting human activity is vigorously growing.

Corresponding Author:

Olena Litovchenko, MD, PhD student,

Professor assistant, Department of Hygiene

and Ecology No.2, Kharkiv National Medical University, Ukraine. E-mail: latyshkaelena@gmail.com
The term "environment" is derived from French "Environ", which means the immediate environment [9]. The environment includes abiotic (physical - hydrosphere, atmosphere, lithosphere) and biotic (living - biosphere) components. The anthroposphere (social factor) is the third key component of the environment. The environment and organisms are two dynamic complex components of nature [8]. The environment affects the life of organisms, including humans. People, in turn, affect the environment even more significantly than other living creatures. The components mentioned above represent the conditions that surround a person at a particular point in time and space. It should be noticed that the components of the environment are explored at a different level. In fact, the physical, chemical and biological components are much more accessible for exploration than the social aspect [11]. Being a relatively young component, the social environment is a special ecosystem that includes the relationship of a person with a person.

Relevance. The social environment develops and spreads as the population grows. In other 
words, humanity itself creates such a component of the environment, expanding its area of influence the day after day. The social environment reflects the traditions in which the person grew up and lives, and the society that the person interacts with. The social component involves economic, natural, human resources that affect the behavior of each individual [2]. The struggle for human existence has become social. The person is incessantly exposed to the social influence, which undoubtedly affects their health and often leads to the depletion of body resources [2, 3]. Modern society is known to be divided into social classes, primarily according to the economic status of the population. Such stratification is clearly noticed when comparing more developed countries with less developed ones, as well as categories of the population of varying level of well-being within the same area [4].

The social environment is considered as an environmental factor that is difficult to be materially introduced and studied as physical process. It is not possible to distinguish the borders of the social component, therefore, the limits of its influence. Thus, aspects of the impact of society on human health are of significantly important nowadays. Health problems do not arise as insulated phenomenon, but are the result of a complex interaction between spatial and temporal circumstances [2].

Society is known to be the most vulnerable environmental factor. In addition, the social environment is extremely dynamic and may have a comprehensive impact on a person and consequently on their health $[4,7]$. Thus, all aspects of society as well as their role in the development of various pathological health conditions should be carefully studied in order to promote the prevention of diseases.

Aspects and components of society. The term "society" covers the immediate environment of a person, their relationship with various communities. The social environment includes industrial and professional infrastructure, the labor market, socio-economic processes, human wellbeing maintenance, social and medical services as well as executive responsibilities. Social influences also depend on racial and national relations, class inequalities, culture, religion and morality. The historical aspect should also be taken into consideration as the impact of society greatly changes throughout centuries. The social environment could be regarded according to several projections, including the household, related networks, the infrastructure of districts, cities and regions [3].
Socio-environmental aspects of human health could be grouped into three categories: environmental epidemiology, social epidemiology and environmental psychology. It is worth noting that these areas are not only insufficiently studied, but also are at a very low level of integration [3, 4]. Social epidemiology is considered as an issue of particular interest. Such an area is one of the most promising areas within the study of environmental factors that affect human health. In fact, society is an elementary unit of social epidemiology. A thorough study of social influence provides new benchmarks for environmental health policies implementing.

Within the study of the impact on human health society includes several components - so-called "social determinants" of health. The World Health Organization (WHO) deciphers the social determinants of health as "the circumstances and conditions in which people are born, grow up, live, work, age, as well as measures taken to combat the disease" [12]. These conditions, in turn, are formed and developed under the control of the economy, the public and politics.

Each component of a person's social environment in terms of impact on human health is considered below.

1. Socio-economic state has the greatest impact on disease development as well as distribution within the population. Social class, gender, ethnicity, profession and income play a certain role in this regard. Low incomes closely correlate to bad health. People of poor socioeconomic status (as an indicator of low income) are more susceptible to acute and chronic diseases. In addition, lack of money contributes to alcoholism, drug addiction, and smoking, which aggravate health problems.

Statistical data collected by the Kansas Department of Health (USA) show that the incidence of diabetes within a category of people whose income is more than $\$ 50000$ per year reaches in average $5.9 \%$. In contrast, among people who earn less than $\$ 15000,16.5 \%$ has diabetes $[4,10]$. What is more, $36.5 \%$ of people with income below $\$ 15000$ is noted to be active smokers, while the population whose income is more than $\$ 50000$, the prevalence of smoking constitutes no more than $10 \%$ [4]. As a result, the last category of the population is expected to be less prone to arthritis, coronary heart disease and stroke.

Health condition is also affected by employment status. Unemployed people have worse state of physical and mental health than 
the employed ones. The most common pathological condition among the unemployed population (aged from 18 to 45 years) is known to be diabetes (about 25\%). Among people having a permanent job, diabetes occurs in $4 \%$ of cases. The prevalence of smoking among the working population is noticed to be two times higher than among those without a job [2].

The pattern of work also matters the incidence of diseases. According to statistical data of 20142016 yy. gathered in the United Kingdom of Great Britain and Ireland, the average life expectancy for people engaged in intellectual work numbers 83 and 78 years old for women and men, respectively. People of manual professions live in average 74 years (women) and 70 years (men) $[2,3]$.

2. Education also plays an important role in the state of health. Education is supposed to be a measure of socio-economic status and consequently a predictor of health. Scientists of the National Institute of Health (the USA) conducted statistical studies indicating that the lack of education significantly reduces the organism resistance to various diseases. In particular, the group of people of higher grade of education (college or institute) suffers from diabetes in $6 \%$ of cases. The prevalence of diabetes among adults who do not have secondary education, estimates at around $14 \%$. In addition, $30 \%$ of the uneducated population suffers from alcoholism and smoking. By contrast, only $7.8 \%$ of educated people tends to have such habits $[3,13]$.

3 . The level of stress is regarded as separate component of the social environment according to the WHO. Social and psychological circumstances could lead to prolonged stress. Anxiety, low self-esteem, social isolation, overstrain at working place and at home increase the prevalence of illnesses and premature death. The close relation between stress and mortality rate is greatly seen when analyzing the social hierarchy of population of industrialized countries [8]. Stressful situations promote the readiness of person's endocrine and nervous systems in order to ensure immediate respond to the emerging threats: the pulse rises, energy reserves are mobilized, blood flow to the muscles increases. The cardiovascular and immune systems are both involved as well. Constant emotional stress depletes the human nervous system, making it more labile [5, 8]. Prolonged stressful state leads to a rise of vulnerability of a person to a number of pathological conditions, such as: infectious diseases, diabetes, hypertension, coronary heart disease, stroke and depression. According to the British Medical Journal (the United Kingdom of Great Britain), the incidence of cardiovascular diseases is 7 times higher in those people who are full-time workers in comparison with those are part-time busy [4].

4. Early initiation of independent life is also a factor that has a significant impact on the health of a person and their children [2]. The health of an adult is known to be laid from birth. Fetal development is an extremely important period within lifetime of an individual. The lack of woman nutrition during pregnancy, stress, severe course of pregnancy, associated with the psychological unpreparedness of the future mother to take care for a child and be responsible for it, leave an imprint on the health of her posterity. The poor physical health of the infant greatly increases the prevalence of cardiovascular and respiratory disorders, disturbance of pancreas, kidneys functioning which increase the risk of morbidity in adulthood. According to the journal "Mothers, babies and health in later life" (Scotland), children with a birth mass of less than $2.5 \mathrm{~kg}$ are affected by diabetes 6 times more frequently than those children whose weight exceeded $4.3 \mathrm{~kg}$ [2].

5. Social conditions. The quality of housing is the key indicator within this area. Poor living conditions promote critical health problems. Poverty and social exclusion are supposed as harbingers of premature death. Migrants and refugees, homeless people, national and ethnic minorities form separate categories of the population that society does not accept. Undoubtedly, the risk of morbidity significantly increases among such population. Pregnant women, children and the elderly are particularly susceptible. The cardiovascular system suffers in the first place $[2,13]$. So-called "social diseases" are also quite frequent. These include: sexually transmitted diseases, tuberculosis, rickets, beriberi, rheumatism. Drunkenness and alcoholism are common as well.

6. Social support makes a significant contribution to the state of human health providing humanity with emotional and practical resources and thus promoting a powerful protective effect on the person. Support can be provided both at the individual and public levels. Low social support is often associated with an increased risk of premature death and poor survival after a heart attack. In particular, among those who are not socially secured, mortality after a heart attack reaches almost $50 \%$, while people who receive 
adequate social support, have poor prognosis after a heart attack only in $25 \%$ of cases [2].

7. Adequate nutrition and access to food resources directly correlates with person's health and well-being. Lack of any components of the human diet promotes metabolism slowdown, insufficient nutritional supply and protein-energy deficiency. Excessive consumption of any components leads to such terrible conditions as cardiovascular insufficiency, diabetes, cancer, degenerative diseases of the eye, obesity and caries [2, 7]. The social side of the issue encompasses the possibility of providing the population with healthy food. In particular, 73\% of Western Europe population tends to consume mainly saturated fats and simple carbohydrates (fast food). Such food is available for all population categories of different socioeconomic status. However, world food trade nowadays does not pay enough attention to the quality of products consumed by society and their impact on the human body. International committees such as Codex Alimentarius (USA), which determine the standards of quality and food safety, are not supported by representatives of public health. Consequently, the long-term consequences of the consumption of low-quality food on human health are not taken into account [6].

Socio-economic conditions lead to differences in the food basket of different categories of the population. In many countries of low development level cheap, energy-intensive products are consumed more often than fresh fruits and vegetables. Such categories of people as young families, the elderly, the unemployed, have the least opportunity to eat well and get all the nutritive substances the body needs. The consumption of fresh vegetables and fruits, legumes, exclusion of starch, animal fat, refined sugars and salt are proved to prevent chronic diseases. According to the United Nations for 2003, the following correlation was traced: the mortality rate from coronary heart disease is inversely proportional to the population supplement with fresh fruits and vegetables in some European and Asian countries. Thus, the highest mortality rate is observed in such countries as Ukraine, Belarus and the Russian Federation, where the supply of fruits and vegetables constitutes less than $150 \mathrm{~kg}$ per person per year. The lowest mortality rates are observed in France, Spain and Italy where more than $300 \mathrm{~kg}$ of fruits and vegetables are annually produced per person [2, 12, 13].

8. Transport is an integral part of the social environment. Transport is closely related to the level of physical activity of a person. Cycling, walking, public transport usage contributes to the preservation of health. Such ways of transportation provide regular physical activity, reduce fatal accidents as well as reduce air pollution. On the one hand mechanization greatly eased human life but on the other hand led to an obesity epidemic. A sedentary lifestyle, car addiction lead to heart disease, diabetes, respiratory diseases and hypoxia, which are associated with lack of fresh air [2]. In addition, the use of private vehicles leads to social exclusion, which, in turn, significantly reduces the interaction of social groups and society as a whole. Undoubtedly, such a relationship is associated with a progressive deterioration of health. Road traffic significantly pollutes the environment, raises the level of noise, which affects the ecological condition of large cities. It is worth noting that this social aspect primarily affects more economically developed countries [3-5].

9. Health care system is another important aspect of society. Access to medical services, including clinical, preventive services and primary health care, determines the ability of society to monitor their own health, both before the onset of the disease and during its progression. Medical services have not been recently considered as a social determinant of health. However, the inequality of access to health care forces worldwide health organizations to change such an ingrained opinion [4]. Social inequality leads to dramatic differences in the attitude of medical representatives to certain groups of the population as well as to the lack of cultural competence, which is provoked by different economic status of patients. Nowadays there is a selective access to medical care, unequal opportunities for maintaining health and ensuring well-being, preventing diseases, providing treatment of the disease and survival in all the countries throughout the world. Prevention, diagnosis and treatment of the disease, the improvement of physical and mental well-being should be provided equally for all individuals, regardless of their social status. Health management must be patient-centered, equally effective and fair. Such important indicators within this area as the availability of health insurance and access to primary medical care are to some extent limited today [8]. The effects mentioned before could be exacerbated by difference in the availability and feasibility of medical services. The economic status of countries and regions is directly related to the development of the health care system. Thus, according to WHO observations, the region of 
Africa has significantly lower levels of medical development as well as environmental protection than the European and American ones [1, 2, 5].

Prospects of the social environment study. The concern of the relationship between socioeconomic aspects and health has expanded over the past few decades. The state of health closely correlates to the social status of the individual in most countries of various level of development. Premature mortality, deterioration of health, chronic pathological conditions, disability, and mental health disorders commonly happen to the category of the population with low social status who is more susceptible to the influence of society. In regard to human health, not only individual characteristics of a person, but also his social environment as well as chemical and physical factors should be taken into account [3, $6,7]$. Social support, the health care system, employment opportunities and education, transport infrastructure, food supply have a global impact on the livelihoods of the human body [7].

It should be noted that the socio-economic status and reputation of the person's neighborhood and surrounding area are also of great importance. Social factors should take into account the peculiarities of lifestyle, hard and risky work, marital status, which are fundamental aspects in the life of each individual. Such quality as resistance should also be considered. It encompasses to the ability to work productively and maintain health, despite the prevailing social circumstances. Thus, the issues of different vulnerability of people and the role of psychosocial aspects in this regard remain unclear, since each individual has different adaptive abilities [6].

Social epidemiology research is extremely difficult due to the frequent lack of awareness of all the characteristics that are relevant to health and healthy behavior. Physical and social aspects of the environment are not aggregated enough. Therefore, hygienists should consider all aspects and components in order to assess the situation sufficiently. Such an approach produces a powerful impetus for the development of typologies at the national as well as international levels. For example, the United States Department of Health and Advisory Committee of the Secretariat for National Health Promotion and Disease Prevention (the USA) recommended "to follow a comprehensive approach according to which all government structures direct their forces towards improving health equally for all categories of the population and reducing inequalities in health maintenance "[6, 8].
The WHO is currently developing several tasks and perspective issues in regard to the social context [12]:

- How are social aspects defined and changed?

- How are the environment and its impact on health limited to humanity?

-What is the role of social environment?

- What methods and tools are needed for a comprehensive study of social and environmental characteristics in terms of health?

The WHO Committee on Social Determinants of Health is actively developing forward-looking models for improving interaction between the social environment and humans. These models are aimed to the following tasks:

- to monitor the influence of social and psychological components of the environment on different age categories; to determine the longterm effects of such an impact on the subsequent life of the individual;

- to pay attention on the social protection of a person, which ensures an even balance between the social strata of the population and their successful cooperation;

- to ensure early diagnosis and the provision of competent medical care, regardless of the social status of the person;

- to eliminate all the concerns related to the protection of the social environment gradually;

- to influence all components of society, taking into account the country's economics and the individual's position in society $[12,13]$.

Conclusions. Therefore, the available data gathered from the conducted studies confirms the impossibility to single out one particular factor that determines the level of influence of the environment on human health. The impact is always made by a few combined factors, both favorable and unfavorable ones. In addition, individuals react to the environmental influence in a different way. Personal social characteristics such as resistance determine the degree according to which the impact is more or less pronounced.

Such areas as environmental epidemiology, environmental psychology and social epidemiology are actively being considered. Significant progress has been recently achieved in social epidemiology exploration. More attention is paid nowadays to the personal development possibilities, well-being maintenance as well as relationships between people and social groups.

However, in regard to social environment new insights and opportunities may contribute to sustainable health only in case if the prospects are united and directed to the uniform purpose. 
Environmental hygiene should be based on assessment of complex effect of all factors on an individual. Only in this case the reaction to the emerging stressors could be explained not only in accordance with individual characteristics, but also with social cohesion and social capital strengthening. The contextual approach to environmental protection requires interdisciplinary cooperation, which is achieved by the analysis of relationship between the environment and health, the influence of policies, thematic integration.

It could be rightfully claimed that restructuring of areas such as social life, work, environment, transport, education, social protection, public health has a profound impact on health. The research and health policy should be greatly coordinated by governmental structures at both local and national levels. Any intervention in the human environment requires considerable time to be prepared and has long-term consequences. Thus it is necessary to have a clear awareness of the future development of the human environment and its interaction with health state. Such an approach will ensure health promotion as well as prevention, treatment of diseases and increase in life expectancy.

Conflict of interests. There is no conflict of interests.

\section{References:}

1. 1. American Community Survey 1-year-estimate (2016). Poverty Status in the Past 12 Months. Retrieved from: https://factfinder.census.gov/faces/tableservices/jsf/pages/productview.xhtml?src=bkmk

2. 2. CSDH (2014). Closing the gap in a generation: health equity through action on the social determinants of health. Final Report of the Commission on Social Determinants of Health. Geneva, World Health Organization. Retrieved from: http://www.who.int/social_determinants/

final_report/csdh_finalreport_2008.pdf

1. 3. Health Council of the Netherlands (2012). Guideline for the identification and protection of high-risk groups. The Hague: Health Council of the Netherlands, 39E.

2. 4. Healthy People 2020 (2010). An Opportunity to Address Societal Determinants of Health in the United States. Secretary's Advisory Committee on National Health Promotion and Disease Prevention Objectives for 2020. Retrieved from: http://www.healthypeople.

gov/2010/hp2020/advisory/SocietalDeterminantsHealth.htm

1. 5. International center for Health and Society (2003). EN: Social determinants of health. The solid facts. Retrieved from: http://www.euro.who.int/_data/assets/pdf_file/0005/98438/e81384.pdf

2. 6. Krieger N. (2001). Theories for social epidemiology in the 21st century: an ecosocial perspective. IntEpidemiol, 30(4):668-77, doi:10.1093/ije/30.4.668.

3. 7. Lavin T., Higgins C., \& Metcalfe O. (2006). Health impact of the built environment. The Institute of Public Health in Ireland, 16-21.

4. 8. Mitchell R., Popham F. (2007). Greenspace, urbanity and health: relationships in England. Journal Epidemiological Community Health, 61(8):681-3.

5. 9. Mondal P. (2015). Meaning, Definition and Components of Environment. Retrieved from: http:/ /www.yourarticlelibrary.com/environment/meaning-definition-and-components-of-environment/6157

6. 10. National Institutes of Health. (2014) Health Disparities. Fact Sheet. U.S. Department of Human and Health Services. Retrieved from: http://report.nih.

gov/nihfactsheets/Pdfs/HealthDisparities(NIMHD).pdf

1. 11. Ponnuswami R. (2014). Components-of-Environment. Retrieved from: https://ru.scribd.com/ doc/14180071/1-1-Components-of-Environment

2. 12. World Health Organization (2014). Social Determinants of Health Key Concepts. World Health Organization. Retrieved from: http://www.who.int/social_

determinants/final_report/key_concepts_en.pdf?ua=1

1. 13. World Health Organization (2011). Rio Political Declaration on Social Determinants of Health. Retrieved from: http://www.who.int/sdhconference/declaration/Rio_political_declaration.pdf

Received: 01-Sep. - 2018

Accepted: 12-Nov. - 2018 